\title{
Toolkits for Retention and Recruitment: Utilization and Outcomes
}

\author{
Sheila Edwards Lange and Joyce W. Yen \\ University of Washington Center for Workforce Development/University of \\ Washington ADVANCE Center for Institutional Change
}

\begin{abstract}
The University of Washington has developed a faculty recruitment toolkit and faculty retention toolkit which have been widely disseminated on the UW campus and off campus at many other colleges and universities. The recruitment toolkit provides guidelines, ideas and strategies for conducting a proactive search for diverse candidates. The retention toolkit is a collection of best practices for retaining faculty across all ranks. In this paper, preliminary findings from search data, and interviews with department chairs and search committees about their experiences utilizing the recruitment toolkit are presented. The paper focuses on the impact that the recruitment toolkit has had on university searches, reviews the elements of the companion retention toolkit and explores implications for future uses of both on other campuses.
\end{abstract}

\section{Introduction}

Given the changing demographics of the nation, the need to diversify the faculty is well understood by academic administrators.[1,2] How to recruit and retain a diverse faculty, however, is still an issue struggled with on many college and university campuses.[1, 3, 4] The primary tool used by many higher education institutions, affirmative action, has failed to produce significant diversity in the faculty. Further, despite its failure, affirmative action has increasingly come under political attack with court cases and statewide anti-affirmative action initiatives.[5, 6]

Over the last decade, higher education research has focused on alternative strategies to affirmative action as the primary means to diversify the faculty. Research has identified two key barriers to achieving faculty diversity: 1) flawed faculty search processes that proliferate faculties that are predominantly white and male;[3] and 2) an academic culture that is slow to embrace and retain women and faculty of color.[4, 7, 8] To address these two barriers, the University of Washington developed a Faculty Recruitment Toolkit in 2000, and recently developed a companion Faculty Retention Toolkit as part of its National Science Foundation sponsored ADVANCE program. This paper summarizes the history and intent of both toolkits, discusses preliminary data from an ongoing research project relative to utilization of the recruitment toolkit and offers recommendations for replication on other campuses.

\section{The University of Washington Context}


The University of Washington (UW) is an urban research institution with two branch campuses, almost 40,000 students and slightly more than 3,000 tenure track faculty as of fall 2003 . Thirtyone percent of the tenure track faculty is female and $14 \%$ is faculty of color. The university hires an average of 225 new faculty members per year. Diversity is considered a key priority by the university's Board of Regents and many initiatives are in place to aid in recruitment and retention of diverse students and faculty.

In October 2001, the University of Washington was one of eight institutions to receive a National Science Foundation ADVANCE Institutional Transformation award to advance women faculty careers in science, engineering, and mathematics (SEM). The five-year cooperative agreement with NSF allows UW to build on existing programs and catalyze institutional transformation. With the grant, the UW created the Center for Institutional Change (CIC). (See www.engr.washington.edu/advance for more details.)

The CIC's vision is a campus in which all SEM departments are thriving, all faculty are properly mentored, and each SEM faculty member is achieving his or her maximum potential. A key premise of the UW ADVANCE program is that cultural changes that are designed to help underrepresented groups invariably improve the environment for everyone. While the CIC's efforts have been focused on 19 science and engineering departments in the College of Engineering and the Science Division of the College of Arts and Sciences, each initiative is evaluated to determine how it can be institutionalized throughout the UW campus.

The CIC's six focus areas are: (1) leadership development for current deans and department chairs, (2) SEM department cultural change, (3) policy transformation, (4) mentoring women in SEM for leadership, (5) transitional support for faculty in SEM, and (6) visiting scholars. Recruitment and retention are key lenses through which to examine these six focus areas. For example, when cultural change efforts challenge underlying assumptions or traditional practices, recruitment and retention processes evolve.

\section{Recruitment and Retention Toolkits}

In 2000, the President's Advisory Committee on Women developed a unique Faculty Recruitment Toolkit for use throughout the campus. Since then, the toolkit has been widely disseminated on the UW campus and off campus at many other colleges and universities. The recruitment toolkit was coupled with campus-wide dissemination by the university president with a clear message encouraging its use, and uniform training was provided to those charged with its use in faculty searches. It is maintained by the university's Equal Opportunity Office, and easily available through the Internet (see

http://www.washington.edu/admin/eoo/forms/ftk 01.html). As part of its ADVANCE program, the UW wrote a companion toolkit which focuses on the retention of faculty.

UW ADVANCE frequently receives requests and comments regarding the toolkits and their availability on the program website. In Spring 2004, Dr. Louis A. Martin Vega, the Dean of the College of Engineering at University of Southern Florida remarked that "[he was] very impressed with the two 'tool kits' on [UW ADVANCE] website that dealt with recruitment and retention of faculty and was wondering if we could obtain your permission to copy those 
documents to hand out at the meeting at FSU [Florida State University] as samples of best practices and of how an institution might put together a plan to better focus on these two important areas." The topics covered in both toolkits are shown below.

\begin{tabular}{|c|c|}
\hline Recruitment Toolkit & Retention Toolkit \\
\hline Faculty Hiring Policies and Procedures & Monitoring the Health and Welfare of Departments \\
\hline Search Tips for Diversifying the Pool & $\begin{array}{l}\text { Transparency in Operations Including Fair and Open } \\
\text { Promotion and Tenure Guidelines }\end{array}$ \\
\hline Resources for Diversity & Creating a Welcoming Department Climate \\
\hline Language and Ads for Announcements & Mentoring \\
\hline Benefits and Resources for New Hires & Valuing Diversity in the Department \\
\hline \multirow[t]{4}{*}{$\begin{array}{l}\text { Resources from other universities and } \\
\text { brochures on UW programs }\end{array}$} & $\begin{array}{l}\text { Supporting Career Development of Pre-Tenure } \\
\text { Faculty }\end{array}$ \\
\hline & Encouraging Mid-Career Professional Development \\
\hline & $\begin{array}{l}\text { Faculty Development Programs, Benefits and } \\
\text { Resources }\end{array}$ \\
\hline & Flexible and Accommodating Policies and Practices \\
\hline
\end{tabular}

The recruitment toolkit was designed to be a flexible document which could be customized by academic departments and their search committees. It provides general guidelines on how to conduct a proactive search for diverse candidates rather the usual strategy of placing an advertisement and sorting applications. Careful crafting of the job announcement language, appointing a diverse search committee and the use of formal and informal networks are a few of the tips offered. Search committees are also advised to take advantage of affinity groups within professional societies when seeking women and minority candidates for positions. The section on benefits and resources available to newly hired faculty emphasizes their importance in the recruitment process, and how over time they might contribute to faculty success and retention.

Faculty retention is as critical as recruitment to the health of a University department. In the past, faculty success has been largely viewed as an individual accomplishment. However, it is now generally acknowledged that what may seem like an individual accomplishment is often the result of subtle, yet vital forms of support. Unfortunately, not all faculty, in particular, women and underrepresented minorities, have had access to such resources and support. Even greater faculty success will result if resources are equitably shared with all faculty. Since faculty replacement costs tend to be much higher than retention costs, faculty retention is as important for economic reasons as it is for departmental morale.

The Faculty Retention Toolkit was developed in the summer of 2003, to assist department chairs in retaining their faculty across all ranks. It is a collection of best practices for nurturing faculty, accommodating individual needs equitably, fostering a supportive environment, and building leaders across the department. Information for the toolkit was gathered from research reports, faculty development resources, and conversations with and presentations from existing 
department chairs and faculty mentors. The toolkit advocates proactive, thoughtful measures which can have great impact on faculty satisfaction.

The retention toolkit has been widely disseminated. In addition to being available online through the UW ADVANCE website and the UW's Equal Opportunity Office (EOO) website, it was distributed to all 19 UW ADVANCE departments in Fall 2003. Furthermore, during the 20032004 academic year, the Faculty Retention Toolkit was also given to participants of the UW campus-wide faculty and staff diversity workshop series hosted by the Provost's office and to other ADVANCE institutions across the country. The Faculty Retention Toolkit was also included in the resource handbook created for UW ADVANCE's first national leadership workshop held in July 2004. Over 25 department chairs and other faculty from eleven institutions from around the country attended the national workshop.

A recent article raised questions about how often search committees actually use the alternative strategies and recommendations offered by those who study faculty hiring.[3] In response to concerns about utilization, the UW ADVANCE program initiated an ongoing research project to assess the impact of the recruitment toolkit on faculty hiring and identify strategies for maximizing utilization of the retention toolkit.

\section{Methodology for analyzing utilization of the recruitment toolkit}

The utilization analysis for the Faculty Recruitment Toolkit includes data from interviews with department chairs, search outcome data collected by the university's Equal Opportunity Office (EOO), and data from interviews with search committee chairs. When the research project is complete, search outcome data from EOO will be analyzed for differences based on toolkit utilization as reported by search committee and academic department chairs.

Each year, the external evaluators of the UW ADVANCE project conduct interviews with the chairs of the nineteen departments participating in the project. The chairs were each asked to discuss their faculty recruitment processes and indicate if the recruitment toolkit was used. Eight of the nineteen chairs ( $42 \%)$ indicated that they actively use the recruitment toolkit in their searches.

To supplement data from the chairs, the authors began with compiling faculty application data as collected by EOO to comply with federal affirmative action regulations. For faculty positions, each applicant is sent an Affirmative Action Information Request Form. Completion of this form is voluntary and it collects information on ethnicity, race, sex, US veteran status, disability, and age (over or under 40). Academic departments then compile the applicant affirmative action data and submit a Faculty Applicant Flow Report to EOO. For the Faculty Applicant Flow Report departments record the number of applicants in each affected class, number of applicants interviewed in each affected class, number of applicants refusing offer in each affected class, affected class status of the applicant proposed for appointment, availability data (as supplied by EOO), total number of qualified applicants, total number interviewed, total number refusing offer, and total number of affirmative action information requests returned. 
Data was recorded from Faculty Applicant Flow Reports for searches conducted in the nineteen ADVANCE departments in the four academic years since Fall 2000. The academic year was defined as July 1 through June 30. The data reported below is preliminary due to inconsistencies in how the data was recorded by search committees and academic departments. The authors found that a few search committees did not distribute the forms to applicants correctly, departments recorded data incorrectly on the Flow Reports, and interpretations of "total number of qualified applicants," varied considerably. To further refine the data, the authors have requested copies of search committee reports for the time period under review, and initiated interviews with search committee chairs. EOO data will be compared to search committee reports and search committee chair interview data to correct inconsistencies. In the interim, it is illustrative to consider the preliminary data in Table 1 below.

\section{Table 1: Summary of Applicant Pool Data UW ADVANCE Departments Academic Years 2000-2004}

\begin{tabular}{|c|c|c|}
\hline & All A & $000-2004$ \\
\hline & \# & $\%$ Female \\
\hline Total new hires & 72 & \\
\hline Total female & 19 & $26.39 \%$ \\
\hline Total forms completed & 4,434 & \\
\hline Total female forms completed & 716 & $16.15 \%$ \\
\hline Total in interview pools & 357 & \\
\hline Total female in interview pools & 74 & $20.73 \%$ \\
\hline Total offers refused & 27 & \\
\hline Total female offers refused & 8 & $29.63 \%$ \\
\hline
\end{tabular}

The proportion of new female hires $(26.4 \%)$ in ADVANCE departments is higher than their proportion in applicant pools $(20.7 \%)$. The data suggests that when women are in the applicant pool, the likelihood of being in the interview pool and being made an offer greatly increases. This point is emphasized when one considers that slightly more than a third of the 74 women in the interview pools were offered a faculty position, and nine of them refused the offer. Clearly the number of faculty refusing offers is also an issue, and one that should be explored in interviews with search committee chairs.

Interviews with the chairs of the search committees in ADVANCE departments were initiated in early fall of 2004. Interviews began with committee chairs for faculty members hired in 2003 or 2004. These search committee chairs were selected because they had recently completed their searches. Moreover, the Faculty Recruitment Toolkit had been available for several hiring cycles, and it was hypothesized that these more recent search committee chairs were more likely to have had exposure to the toolkit.

The interviews had multiple thrusts in addition to verifying data from Applicant Flow Reports. First, the interviews served to diagnosis the search committee chair's familiarity with the Faculty Recruitment Toolkit and steps taken by the committee to increase the diversity of the applicant pool. Second, search committee chairs were given an opportunity to identify areas for 
improvement and/or additional resources and information which could help future search committees. For example, search committee chairs were asked to identify the most challenging aspects of the search process. Their answers will guide improvements to the toolkit and to search committee support structures. Lastly, climate both during and after the interview was also addressed through questions regarding customizing the interview process and relationships with the candidate after an offer has been extended and once the new hire starts.

\section{Findings}

The initial interviews with seven faculty search committee chairs representing departments in the College of Arts and Sciences and the College of Engineering, revealed that all the interviewees were familiar with the Faculty Recruitment Toolkit. However, each search committee used the toolkit to varying degrees. General observations include the following:

- In the College of Engineering the Dean meets with each search committee at the start of the process to discuss search goals and to stress the importance of casting the net widely to help promote diversity in the applicant pool. Moreover, the dean points the search committee to the resources made available through the Faculty Recruitment Toolkit. Departments are proactively encouraged to make use of the resource.

- Several search committee chairs noted that the toolkit was a good tool for comprehensive information on diversifying the applicant pool. While the various lists of recent $\mathrm{PhD}$ graduates and suggestions for advertising placements were helpful, several search committee chairs expressed disappointment that the efforts did not yield as good results as they had hoped. In some cases, getting the faculty to buy into potential candidates and acknowledge implicit biases in evaluating candidates and/or broadening the search were the greater challenges.

- Most searches continue to rely on departmental faculty networking with their colleagues to identify potential candidates. It was noted by several search committee chairs that perhaps more effort could be done to reach out to institutions which have a history of producing $\mathrm{Ph}$.D. students from underrepresented minority groups. However, it was suggested that this effort is best directed at the college level rather than at a departmental level.

- Departments which conscientiously had a broad position definition received many more applications than those which had positions advertising subspecialty needs. Searches that set out to identify the best candidate in a broad discipline, rather than a narrowly defined subfield experienced more diversity in their candidate pools.

- One of the most challenging aspects of the search process is dual career situations. All search committee chairs experienced difficulties associated with this topic. The most common difficulty cited was negotiating with other units on campus to try to find suitable accommodations for the partner or spouse. Much time and energy was devoted to addressing dual career concerns. All departments seem to acknowledge that this issue is part of the hiring process now and that it does not impact the evaluation of a candidate. 
The departments wish to bring in the best faculty and attempt to be as accommodating as possible.

- Finally, any relationship which may have developed between the search committee chair and the candidate during the application interview process generally receives little additional cultivation once an offer has been made. Usually the search committee chair defers to the department chair in negotiations with the candidate, and then relies on colleagues in the new hire's technical area to mentor and guide the new faculty member once they join the department.

- Few of the committees had a system in place to track potential female and minority candidates. Those who did found that either an advocate or administrative support person who monitored how diverse applicants fared in the process made a difference in the diversity of the interview pools. The advocate constantly brought up new options and kept the department thinking about diverse candidates.

\section{Summary}

The authors will continue to conduct interviews with search committee chairs and reconcile the EOO data with interview and search committee report data. A limitation of the EOO data is its voluntary nature. Faculty candidates can choose not to return the Affirmative Action Information Request form and impact what is known about the diversity of applicant pools. It is clear that accurate data collection needs to become a priority for further research purposes. Other issues needing further research and/or attention include the dual career issues, the influence of Deans in the process, and the role of implicit biases and/or departmental politics during the search process.

\section{References:}

[1] A. L. Antonio, "Diverse student bodies, diverse faculties," in Academe, vol. 89, 2003, pp. 14-17.

[2] C. Turner, Diversifying the faculty: A guidebook for search committees. Washington, DC: Association of American Colleges and Universities, 2002.

[3] D. Smith, C. S. V. Turner, N. Osei-Kofi, and S. Richards, "Interrupting the usual: Successful strategies for hiring diverse faculty," Journal of Higher Education, vol. 75, pp. 133-160, 2004.

[4] A. Aguirre, Women and minority faculty in the academic workplace: Recruitment, retention and academic culture, vol. ASHE-ERIC Higher Education Report Volume 27, Number 6. San Francisco, CA: Jossey-Bass Inc., 2000.

[5] V. Washington and W. Harvey, "Affirmative rhetoric, negative action: African-American and Hispanic faculty at predominantly White institutions," ERIC Clearinghouse on Higher Education, Washington, DC, Descriptive RI88062014, 1989. 
[6] W. G. Tierney and J. K. Chung, "Affirmative action in a post-Hopwood era," in The racial crisis in American higher education, revised edition, W. Smith, K. Lomotey, and P. Altbach, Eds. Albany, NY: SUNY Press, 2002, pp. 271-283.

[7] W. R. Allen, E. Epps, E. Guillory, S. Suh, M. Bonous-Hammarth, and M. Stassen, "Outsiders within: Race, gender and faculty status in U.S. higher education," in The racial crises in American higher education, revised edition, W. Smith, P. Altbach, and K. Lomotey, Eds. Albany, NY: SUNY Press, 2002, pp. 189-220.

[8] D. Owens, "Black women in higher education: Negotiating the cultural workplace," in Building bridges for women of color in higher education: A practical guide to success, C. Battle and C. Doswell, Eds. Lanham, MD: University Press of America, 2004, pp. 76-90.

SHEILA EDWARDS LANGE - Sheila Edwards Lange is a doctoral candidate in the Educational Leadership and Policy Studies at the University of Washington. She is the Associate Director of Research in the Center for Workforce Development, and is part of the internal evaluation team for the UW ADVANCE program.

JOYCE W. YEN -Joyce W. Yen received her Ph.D. in Industrial and Operations Engineering from the University of Michigan, Ann Arbor. She was a former assistant professor of Industrial Engineering at the University of Washington and now serves as the Program/Research Manager for the University of Washington's NSF-funded ADVANCE Center for Institutional Change. 